UDC 94(470.45):378

Submitted: 09.01.2020

LBC 63.3(2Рос-4Вог)64-7

Accepted: 03.04.2020

\title{
CLASSICAL UNIVERSITY EDUCATION IN VOLGOGRAD REGION: ORIGIN AND DEVELOPMENT
}

\author{
Taisiya V. Yudina \\ Volgograd State University, Volgograd, Russian Federation
}

\begin{abstract}
Introduction. The article covers history waypoints of the corporate culture, tradition, emblems of Volgograd State University, its corporate ideology and the role of the University in the regional community. The author enlightens the activity and responsibility of the rector department and faculties in terms of the development of the University as region's leader of science, education and culture. Methods and materials. The principles of historicism and objectivity were used as a methodological base of the research. The study is based on scientific papers on the role of university education in modern society and corporate cultural space in the university community. Analysis. The core activity and focused informational work of the University has allowed to form its positive image. Special attention is paid to the appearance of higher education institutions in the region and the establishment of Volgograd State University. The author studies the contribution of the University to the social-economic, public and cultural sphere of region's life. Results. The main conclusion of the article is that nowadays classic university education leads to forming the social elite, increases the level of education and culture in the regional community. The program of transforming Volgograd State University into the University Centre of innovative, technological and social development of the region allows to reach success for not only the University, but for the whole region.

Key words: region, classical university, image, education, science, corporate culture, traditions.

Citation. Yudina T.V. Classical University Education in Volgograd Region: Origin and Development. Vestnik Volgogradskogo gosudarstvennogo universiteta. Seriya 4. Istoriya. Regionovedenie. Mezhdunarodnye otnosheniya [Science Journal of Volgograd State University. History. Area Studies. International Relations], 2020, vol. 25, no. 2, pp. 147-155. (in Russian). DOI: https://doi.org/10.15688/jvolsu4.2020.2.10
\end{abstract}

УДК 94(470.45):378

ББК 63.3(2Рос-4Вог)64-7
Дата поступления статьи: 09.01.2020

Дата принятия статьи: 03.04.2020

\section{КЛАССИЧЕСКОЕ УНИВЕРСИТЕТСКОЕ ОБРАЗОВАНИЕ В ВОЛГОГРАДСКОМ РЕГИОНЕ: СТАНОВЛЕНИЕ И РАЗВИТИЕ}

\author{
Таисия Васильевна Юдина \\ Волгоградский государственный университет, г. Волгоград, Российская Федерация
}

\begin{abstract}
Аннотация. В статье освещены вопросы формирования корпоративной культуры, традиций, символики Волгоградского государственного университета, корпоративной идеологии; роли университета в региональном сообществе; деятельности и ответственности ректорского корпуса, профессорско-преподавательского состава по развитию университета как ведущего научно-образовательного и культурного регионального центра. Методологическую основу исследования составили общеисторические принципы историзма и 응 объективности. Основная деятельность университета и целенаправленная информационная работа позволиतิ ли сформировать его положительный имидж. Акцентировано внимание на появлении высших учебных ضे заведений в регионе и создании Волгоградского государственного университета. Исследованы достижения и вклад университета в социально-экономическую, общественную, культурную жизнь региона. Результатом исследования является вывод о том, что в современных условиях классическое университетское образова오 ние способствует формированию социальной элиты, повышению уровня образования и культуры регио(?) нального сообщества. Реализация Программы трансформации Волгоградского государственного универси-
\end{abstract}




\section{УНИВЕРСИТЕТЫ ХХ ВЕКА: ИСТОРИЯ И ПОЛИТИКА}

тета в Университетский центр инновационного, технологического и социального развития региона позволяет успешно эволюционировать не только университету, но и региону в целом.

Ключевые слова: регион, классический университет, имидж, образование, наука, корпоративная культура, традиции.

Цитирование. Юдина Т. В. Классическое университетское образование в Волгоградском регионе: становление и развитие // Вестник Волгоградского государственного университета. Серия 4, История. Регионоведение. Международные отношения. - 2020. - Т. 25, № 2. - С. 147-155. - DOI: https://doi.org/10.15688/ jvolsu4.2020.2.10

Введение. Большинство человеческих знаний о мире формируются на уровне имиджей. Имидж, или целенаправленно сформированный образ организации, призван оказывать эмоционально-психологическое воздействие в целях его популяризации.

Повышению современного имиджа российских университетов способствуют формирование корпоративной культуры, активизация музейной и выставочной работы и деятельность ректорского корпуса, профессорско-преподавательского состава по формированию университетов как ведущих научно-образовательных и культурных региональных центров. Стремление отстаивать благородные цели развития образования и науки способствует повышению роли университетов в жизни общества и прогрессу регионов и страны.

Методы и материалы. Методологической основой исследования явились традиционные принципы исторического исследования: научной объективности, историзма. Принцип научной объективности позволил рассматривать влияние классического университетского образования на социально-экономическую, общественную, культурную жизнь региона. В соответствии с принципом историзма этапы и основные направления становления и развития Волгоградского государственного университета удалось исследовать объективно, опираясь на научную литературу. Исследование базируется на научных трудах, посвященных роли университетского образования в современном обществе, корпоративного культурного пространства в университетском сообществе.

Анализ. Силу и устойчивость корпоративной культуры более всего определяют традиции. С традициями университета знакомятся преподаватели и студенты, впервые переступившие его порог. Например, в Волгоградском государственном университете (ВолГУ) в День знаний каждый первокурсник узнает историю университета, знакомится с его правилами, достижениями, людьми, структурой и символами.

Историю Волгоградского государственного университета, его традиции и достижения бережно хранит Музей истории университета, где собраны уникальные экспонаты, использующиеся в учебной, научной и воспитательной работе.

Не только Волгоградский государственный университет, но и каждый институт ВолГУ имеет свои разработанные герб и девиз, отражающие специфику тех направлений подготовки, по которым обучаются студенты. Гербы университета и институтов (см. рис. 1 и 2 герба ВолГУ, иллюстрирующие его изменения и совершенствование) составляют единую систему символики, которая представлена в оформлении интерьера, в печатной продукции, на сайте и в презентационных материалах. Она стала своеобразным способом идентификации университета, формируя особый архетип его восприятия в регионе. Университет имеет свои гимн и флаг. Гимном университета открываются научные конференции и симпозиумы, спортивные состязания, студенческие мероприятия. С торжественной линейки в День знаний, звучания гимна, внесения знаменной студенческой группой флага университета и штандартов институтов начинается первый учебный год для нового университетского пополнения.

Корпоративная культура во многом определяется уровнем организации труда в университете. Современной компьютерной техникой оснащены все кафедры, институты, центры и лаборатории, компьютеризированы все рабочие места управленческого аппарата, функционируют высокотехнологичные аудитории, единая информационная сеть. И преподаватели, и студенты владеют современными информационными технологиями, исполь- 
зуют их в учебном процессе, научно-исследовательской работе.

С каждым годом благоустраивается университетская территория, модернизируются аудитории и залы, кафе и общежитие. Красивые горки, газоны, клумбы, светлые коридоры, удобные аудитории, уютные кафе создают особую атмосферу внимания и заботы о студентах и сотрудниках, во многом определяющую эмоциональное состояние тех, кто каждый день обучается и трудится в университете.

Современный уровень организации рабочих мест преподавателей, сотрудников и студентов является важным фактором повышения поведенческой культуры корпоративного сообщества [1, с. 135]. Культура работников и культура организации того пространства, в котором учатся студенты, чрезвычайно важны. Еще в 2007 г. на студенческом Форуме был принят Этический кодекс студента Волгоградского государственного университета, в 2008 г. - Этический кодекс преподавателя и сотрудника ВолГУ.

Активизация выставочной работы также способствует повышению современного имиджа университета. Проводившиеся темы выставок, как «Университетские массмедиа: соединяя пространство и время», «Волгоградский государственный университет и Российская академия наук», «Развитие физкультуры и спорта в Волгоградском государственном университете», «30 лет Волгоградскому государственному университету» и др., бесспорно, были направлены на развитие корпоративной идеологии.

Основные элементы корпоративной идеологии сводятся к следующим:

- наш университет - один из ведущих в образовательном пространстве региона;

- университетская деятельность полезна для общества;

- университет заботится о каждом своем сотруднике и студенте;

- от каждого сотрудника и студента зависит успех университета;

- от успеха университета зависят благополучие каждого сотрудника и качество подготовки студента.

Однако имидж университета тесно связан не только с тем, что происходит внутри него, но и с тем, что происходит за его преде- лами. Положительный имидж не появляется самостоятельно, он формируется основной деятельностью университета и целенаправленной информационной работой [5].

Позитивное отношение к университету отражают публикации в средствах массовой информации о его достижениях в различных сферах деятельности. Как вуз с многоступенчатой системой обучения, социально развитой инфраструктурой Волгоградский государственный университет позиционирует себя как центр образования, науки, культуры и социальной активности.

Система классического университетского образования в современных российских условиях выполняет просветительскую, объединяющую и модернизационную роль [6]. Д.С. Лихачев справедливо заметил: «Культура не сосредоточена только в университетских и академических центрах. Культуру нельзя развивать, ориентируя ее на два или три гигантских города, слабо связанных со всей остальной страной. Должно быть приостановлено разбухание таких городов, как Москва и Петербург, еще и потому, что в их “каменных джунглях" антикультура растет быстрее, чем собственная культура» [4, с. 18]. Однако именно классическое университетское образование способствует формированию социальной элиты, повышению уровня образования и культуры регионального сообщества.

Решение об открытии классического университета в Волгограде было принято в 1974 году. Но еще в начале XX в. царицынские думцы неоднократно обращались в Министерство просвещения об открытии в Царицыне высшего учебного заведения [3, c. 122]. В 1930-е гг. в Сталинграде (в 1925 г. Царицын был переименован в Сталинград) появились первые вузы - механический, педагогический, медицинский; позже - сельскохозяйственный, институт инженеров городского хозяйства и др. Отраслевые институты осуществляли подготовку кадров для индустриального Сталинграда (с 1961 г. Волгограда), готовили специалистов для сельского хозяйства, медицины и народного образования. Но «город ждал открытия университета», вспоминает Максим Матвеевич Загорулько, первый ректор Волгоградского государственного университета. 
Распахнувший свои двери для первых студентов почти 40 лет назад (первые 250 студентов поступили в университет в 1980 г.) Волгоградский государственный университет сегодня - широко известный вуз как в стране, так и вне ее.

Значительная роль в становлении и развитии регионального университетского образования принадлежит ректорскому корпусу. С 1980 по 1995 г. ВолГУ возглавлял Максим Матвеевич Загорулько, с 1995 по 2014 г. - Олег Васильевич Иншаков, с 2014 по 2020 г. - Василий Валерьевич Тараканов. В течение первых 15 лет (1980-1995 гг.) М.М. Загорулько, имевший опыт руководства вузом, формировал кадровый потенциал преподавательского состава классического типа, укреплял международные связи. На указанном этапе много внимания уделялось оснащению оборудованием учебных аудиторий. Активная жизненная позиция, значительные усилия М.М. Загорулько по развитию культуры волгоградского региона, его высокий авторитет среди общественности позволили ему уже 3 декабря 1983 г. возглавить Совет ректоров вузов г. Волгограда. В последующие годы благодаря его энергичной работе, взаимодействию с областными и районными властями были открыты 5 филиалов университета в Волгоградской области, 1 филиал в Астраханской области. Волгоградский государственный университет оказывал заметное влияние на развитие региона. Аспирантуpa, диссертационные советы, новые специальности, компьютерные классы, наполнение книжного фонда научной библиотеки - количественные и качественные показатели необходимых элементов развития университета формировались значительно выросшим научно-педагогическим коллективом ВолГУ. Воздействие университета на культурную и общественную жизнь проявлялось в различных сферах. Студенты и преподаватели открывали новые страницы истории Сталинградской битвы, активно участвовали в городских и областных конференциях, конкурсах, продолжали строить вуз, представляли Волгоградскую область на всероссийском и всесоюзных уровнях. Первые выпускники ВолГУ в 1985 г. были распределены в вузы, ссузы, школы, краеведческие музеи, некоторые из них стали работать в райкомах комсомола и партии.
К середине 1990-х гг. Волгоградский государственный университет - признанный образовательный, научный и культурный региональный центр. При этом успешно решались не только вопросы развития материально-технической базы классического университета, но и социальные проблемы коллектива. Преподавателям с ученой степенью кандидата и доктора наук предоставлялось жилье, была решена проблема доставки сотрудников и преподавателей с работы и на работу служебным транспортом. Транспортные развязки и дороги являлись в тот период одним из самых острых вопросов социально-экономического развития Волгограда. Таким образом, решение транспортной проблемы для работников университета, возведенного в географическом центре города, в 1990-е гг. оказалось очень своевременным.

При становлении университета значительное внимание уделялось развитию библиотеки, собиранию литературы по всей стране. Университеты, ученые передавали в дар ВолГУ научную литературу, личные библиотеки. Строительство и открытие в 2014 г. нового библиотечного корпуса способствовало превращению крупнейшей библиотеки в Волгоградской области, предмету особой гордости вуза в один из центров научной информации Юга России. Около 800 тыс. экземпляров учебной, научной, художественной, периодической литературы предоставлены студентам, аспирантам, преподавателям университета и жителям Волгограда и области. Постоянно пополняются электронные научно-образовательные издания. Электронная библиотека крупнейшая в Волгограде.

Первому ректору приходилось не только формировать команду единомышленников, обеспечивать учебный процесс, создавать научные лаборатории, но и строить университет, общежитие. Не хватало рук на стройке, по инициативе М.М. Загорулько создавались студенческие строительные отряды. Пройдя краткосрочное обучение, будущие историки, филологи, физики и математики на практике осваивали строительные профессии.

«Добывать высокую славу университета» приходилось и первым абитуриентам в составе «золотого отряда». «Золотой отряд»17-20-летние девушки и юноши, имевшие крас- 
ные дипломы и золотые медали, сдавшие первый экзамен на «отлично» и освобожденные от сдачи остальных вступительных испытаний, достраивали со своими первыми преподавателями в августе 1980 г. учебные аудитории, столовую, спортивный зал и готовились к проведению торжественной линейки 1 сентября [8, с. 117]. Так добровольная молодая рабочая сила, привлеченная в коллектив с красивым названием «золотой отряд», помогала решать вопрос подготовки здания к первому учебному году.

1 сентября 1980 г. торжественную линейку университета посетили первые лица области: первый секретарь Волгоградского обкома КПСС Л.С. Куличенко и его помощники. Открытие университета действительно было долгожданным, ярким и значимым событием в истории региона.

Дальнейшее перспективное развитие университета связано с Олегом Васильевичем Иншаковым. Благодаря его профессионализму, неординарным решениям, активной гражданской позиции, творческому духу университет стал одним из ведущих вузов Южного федерального округа. Была модернизирована структурная организация высшего учебного заведения, созданы новые факультеты и институты, укреплена материальная и финансовая база университета, его кадровый состав.

Научно-образовательные центры, научнотеоретический журнал «Вестник Волгоградского государственного университета», малые инновационные предприятия, высокие технологии в образовании, электронный учебно-методический комплекс - свидетельство активной деятельности О.В. Иншакова, качества образования, высокого научного потенциала университета, российской и мировой известности вуза.

Огромен вклад О.В. Иншакова в развитие экономики региона. Им разработаны стратегические программы, обоснованы направления и механизмы стратегической модерни- зации экономики Юга России. Его рекомендации используются в региональной хозяйственной практике.

Преемственность поколений ректоров ВолГУ М.М. Загорулько и О.В. Иншакова можно проследить в их афоризмах.

Значительное влияние на социально-экономическую, общественную, культурную жизнь региона оказывают ученые Волгоградского государственного университета, ориентируясь на инновационное развитие приоритетных научных направлений и их интеграцию в экономику региона. В содружестве с Российской академией наук и вузами Волгограда подготовили и выпустили в свет «Экономическую энциклопедию Волгоградской области», «Энциклопедию Волгоградской области», «Археологическую энциклопедию Волгоградской области», «Этнографическую энциклопедию Волгоградской области», «Стратегию социально-экономического развития Волгоградской области (2008-2025 гг.)». Мультимедийный путеводитель «Добро пожаловать в Волгоград», подготовленный на нескольких языках преподавателями и студентами Волгоградского государственного университета с использованием технологии дополненной реальности, был особенно востребован отечественными и иностранными болельщиками в дни Чемпионата мира по футболу, проходившему в Волгограде в 2018 году.

Вклад студентов в жизнь региона действительно не менее значителен. Эффективное осуществление социально-воспитательной политики в университете, направленное на развитие особого социокультурного пространства - среды вуза, способствует реализации социально-воспитательного компонента учебного процесса. Она включает развитие студенческого самоуправления, участие обучающихся в работе общественных организаций, спортивных и творческих клубов, научных

$$
\text { М.М. Загорулько }
$$

О.В. Иншаков

\begin{tabular}{l|l} 
Ректор - это еще не университет & Университет - это уже не ректор \\
\hline Должность дают, а власть берут & «Должность дают, власть беруг», а честь берегуг \\
\hline Важное- впереди срочного & Важное - впереди срочного, но позади вечного \\
\hline Побеждает терпеливый & Начало победы - в конце терпения \\
\hline Ни одного дня без собственно созданной радости & Ни дня без собственно розданной радости \\
\hline $\begin{array}{l}\text { Объяснить можно все, даже преступление, } \\
\text { оправдать нельзя }\end{array}$ & $\begin{array}{l}\text { Оправдать можно все, даже наказание, объяснить - } \\
\text { нужно [2] }\end{array}$
\end{tabular}


студенческих обществ, волонтерского объединения и позволяет студентам ВолГУ активно и успешно презентовать себя и свой вуз в региональных, всероссийских конкурсах, олимпиадах, выставках, проектах и т. д. Волгоградский государственный университет является региональным ресурсным добровольческим центром, транслирующим заинтересованным субъектам практики и методики вовлечения молодежи в добровольческую деятельность, технологии управления волонтерами. Созданные в университете условия для развития социальных, профессиональных и личностных компетенций обучающихся; воспитание самостоятельных, ответственных студентов и их подготовка к жизни в современных условиях способствуют укреплению авторитета ВолГУ на рынке образовательных услуг [7, с. 26-28], востребованности выпускников в региональной экономике.

Повышению имиджа университета как ведущего научного центра России, продвижению работ исследователей ВолГУ на международный уровень способствует его издательская деятельность. Результатом профессиональной и активной работы редакционных коллегий журналов, издательства ВолГУ, научной деятельности ученых является включение в состав крупнейших мировых баз данных научной периодики «Вестника Волгоградского государственного университета. Серия 4. История. Регионоведение. Международные отношения» (Web of Science, Scopus), «Вестника Волгоградского государственного университета. Серия 2. Языкознание» (Web of Science) и журнала «Математическая физика и компьютерное моделирование» (Math SciNet). Также университетское издательство ежегодно с 2015 г. проводит в Москве, на крупнейшей российской книжной ярмарке-выставке «Красная площадь», презентации научных трудов ученых ВолГУ.

На современном этапе Василием Валерьевичем Таракановым много внимания уделялось укреплению достигнутых результатов и созданию новых проектов развития университета. Инжиниринговый центр, региональный центр дополнительного образования (Дом научной коллаборации им. 3.В. Ермольевой), университетская «Точка кипения», Центр общественной дипломатии - органи- зации, способствующие большей открытости и необходимости университета для региона. Реализация с 2017 г. Программы трансформации Волгоградского государственного университета в Университетский центр инновационного, технологического и социального развития региона позволяет успешно эволюционировать не только университету, но и региону в целом.

Результаты. Развитие образования и науки - основа прогресса российского общества. Историческая роль и ответственность университетов как центров образования, науки и культуры России и регионов при этом значительна. Роль и ответственность ректоров университетов, научно-педагогического сообщества не менее важна для достижения высоких целей.

Важно подчеркнуть, что в Волгоградском государственном университете проводится большая работа по сохранению и воспроизводству системы ценностей. Корпоративным традициям в этом плане отведена ведущая роль. Под термином «традиции» обычно понимается поддержание всей совокупности ценностных ориентаций. Особенность «традиции» как феномена духовной культуры заключается в приоритетной роли «формы». Эту роль выполняет корпоративная символика (герб, флаг, гимн университета; гербы и штандарты институтов и фирменные цвета университета: синий, белый, золотой), а также традиционные по своей сути мероприятия, посвященные праздникам (День университета - 24 мая, День знаний -1 сентября и др.). С дальнейшим развитием Волгоградского государственного университета для расширения коммуникаций, позиционирования во внешней среде потребовалась разработка стандартов визуального стиля университета (см. рис. 3).

Предоставляемое Волгоградским государственным университетом классическое образование позволило сформировать в Волгоградском регионе социально-культурную и профессионально-образовательную среду, в которой вырастает элита современного российского общества. Образовательные программы классического университета имеют потенциал для серьезного продвижения в глобальном научном и образовательном пространстве. 
T.В. Юдина. Классическое университетское образование в Волгоградском регионе: становление и развитие

ПРИЛОЖЕНИЕ

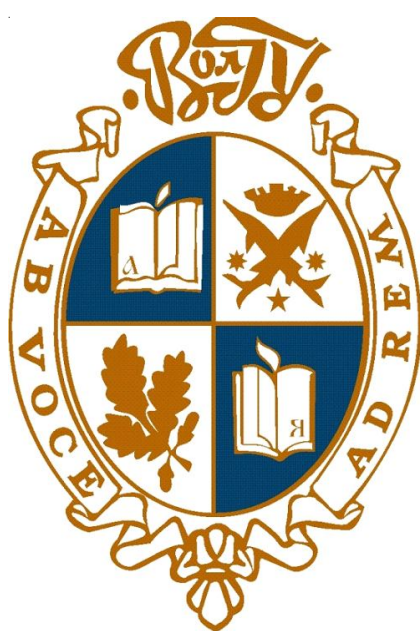

Рис. 1. Эскиз герба университета, выполненный В.Э. Ковалем и одобренный Ученым советом ВолГУ весной 1996 года

Photo 1. Sketch of the university coat of arms made by V.E. Koval and approved by the Academic Council of VolSU in spring 1996

Примечание. Предоставлено из архива издательства ВолГУ.

Note. Provided from the archive of the VolSU publishing house.

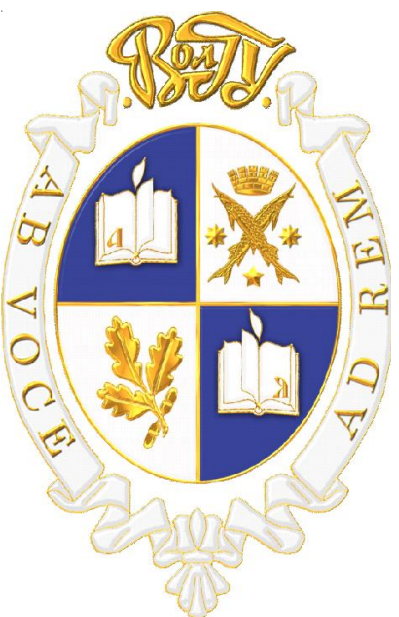

Рис. 2. 2-й вариант герба университета, используемый с 2014 года

Photo 2. The second version of the university coat of arms used since 2014

Примечание. Источник: https://volsu.ru/sveden/galleries/symbolism.

Note. Source: https://volsu.ru/sveden/galleries/symbolism.

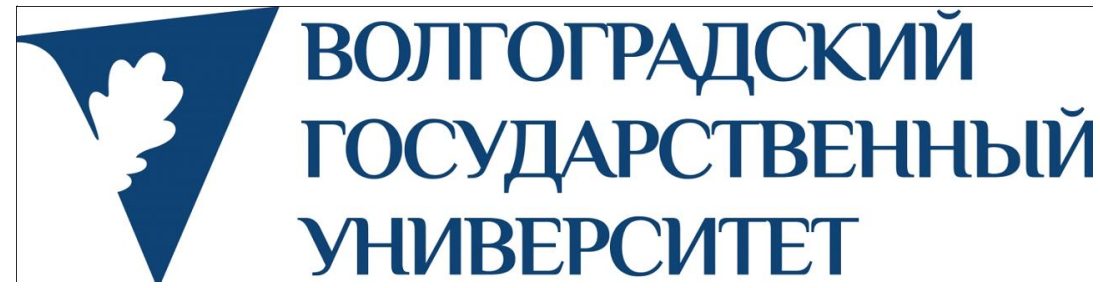

Рис. 3. Визуальный стиль ВолГУ

Photo 3. The visual style of VolSU

Примечание. Источник: https://volsu.ru/sveden/galleries/symbolism.

Note. Source: https://volsu.ru/sveden/galleries/symbolism. 


\section{СПИСОК ЛИТЕРАТУРЫ}

1. Дрожжина, Е. Е. Матрица социализации личности в социокультурной среде университета / Е. Е. Дрожжина // Вестник Волгоградского государственного университета. Серия 7, Философия. Социология и социальные технологии. - 2011. № 1 (13). - С. 132-137.

2. Загорулько, М. М. Ректорская игра в афоризмы / М. М. Загорулько, О. В. Иншаков // Вестник Волгоградского государственного университета. Серия 6, Университетское образование. - 2004. Вып. 7. - С. 149.

3. Литвинова, И. Н. Частная форма благотворительности в г. Царицыне / И. Н. Литвинова // Вестник Волгоградского государственного университета. Серия 7, Философия. Социология и социальные технологии. -2011. - № 2 (15). - С. 120-123.

4. Лихачев, Д. С. Великая культура примирительна по своей сути / Д. С. Лихачев // Гуманитарная культура как фактор преобразования России. СПб., 1997.- С. 17-18.

5. Матвеева, А. С. Коммуникативные технологии создания позитивного имиджа университета на страницах печати / А. С. Матвеева // Креативные процессы в экономике : II Междунар. науч.-практ. интернет-конф. - Волгоград : Волгоград, 2010. Электрон. текстовые дан. - Режим доступа: http:// www.volsu.ru /s_conf /10/ (дата обращения: 25.11.2019). - Загл. с экрана.

6. Садовничий, В. А. Вступительное слово ректора Московского университета, Президента Евразийской ассоциации университетов, академика РАН / В. А. Садовничий // Университеты и общество. Сотрудничество университетов в XXI веке : материалы Второй Междунар. науч.-практ. конф. университетов. - М. : МАКС Пресс, 2014. - С. 5.

7. Юдина, Т. В. Социально-воспитательный компонент образовательного процесса в высшем учебном заведении / Т. В. Юдина, Е. Е. Дрожжина, Н. А. Николенко. - Волгоград : Изд-во ВолГУ, 2013. - 196 с.

8. Юдина, Т. В. С кого все начиналось? (К юбилею М.М. Загорулько) / Т. В. Юдина // Вестник Волгоградского государственного университета. Серия 6, Университетское образование. - 2004. Вып. 7. - С. 117-118.

\section{REFERENCES}

1. Drozhzhina E.E. Matritsa sotsializatsii lichnosti v sotsiokulturnoy srede universiteta [Matrix of Personal Sociolization Within Social and Cultural University Context]. Vestnik Volgogradskogo gosudarstvennogo universiteta. Seriya 7, Filosofiya. Sotsiologiya and Sotsialnye Tekhnologii [The Science Journal of
Volgograd State University. Philosophy. Sociology and Social Technologies], 2011, no. 1 (13), pp. 132-137.

2. Zagorulko M.M., Inshakov O.V. Rektorskaya igra $\mathrm{v}$ aforizmy [Rector's Game of Aphorisms]. Vestnik Volgogradskogo gosudarstvennogo universiteta. Seriya 6, Universitetskoe obrazovanie [Science Journal of Volgograd State University. University Education], 2004, iss. 7, p. 149.

3. Litvinova I.N. Chastnaya forma blagotvoritelnosti v g. Tsaritsyne [Private Form of Charity in Tsaritsyn]. Vestnik Volgogradskogo gosudarstvennogo universiteta. Seriya 7, Filosofiya. Sotsiologiya and Sotsialnye Tekhnologii [The Science Journal of Volgograd State University. Philosophy. Sociology and Social Technologies], 2011, no. 2(15), pp. 120-123.

4. Likhachev D.S. Velikaya kultura primiritelna po svoey suti [Great Culture Is Essentially Accomodating]. Gumanitarnaya kultura kak faktor preobrazovaniya Rossii [Humanistic Culture as a Transformation Factor of Russia]. Saint Petersburg, 1997, pp. 17-18.

5. Matveeva A.S. Kommunikativnye tekhnologii sozdaniya pozitivnogo imidzha universiteta na stranitsakh pechati [Communicative Technologies of Creating a Positive Public Image of a University in Newspapers]. Kreativnye protsessy v ekonomike: II Mezhdunar. nauch.-prakt. internet-konf. [Creative Processes in Economics. $2^{\text {nd }}$ International Scientific and Practical Internet Conference]. Volgograd, Volgograd, 2010. URL: http://www.volsu.ru/s_conf/10/ (accessed 25 November 2019).

6. Sadovnichiy V.A. Vstupitelnoe slovo rektora Moskovskogo universiteta, Prezidenta Evraziyskoy assotsiatsii universitetov, akademika RAN [Opening Speech of the Rector of Moscow University, President of the EUA, Member of the Russian Academy of Sciences]. Universitety i obshchestvo. Sotrudnichestvo universitetov $v$ XXI veke: materialy Vtoroy Mezhdunar. nauch.-prakt. konf. universitetov [Universities and Society. Universities' Partnership in the $21^{\text {st }}$ Century. Proceedings of the Second International Scientific and Practical University Conference]. Moscow, MAKS Press Publ., 2014, p. 5.

7. Yudina T.V., Drozhzhina E.E., Nikolenko N.A. Sotsialno-vospitatelnyy komponent obrazovatelnogo protsessa $v$ vysshem uchebnom zavedenii [SocialPedagogic Component of the Educational Process at University]. Volgograd, Izd-vo VolGU, 2013. 196 p.

8. Yudina T.V. S kogo vse nachinalos? (K yubileyu M.M. Zagorulko) [Who with Did It Start? (To the Anniversary of M.M. Zagorulko)]. Vestnik Volgogradskogo gosudarstvennogo universiteta. Seriya 6, Universitetskoe obrazovanie [Science Journal of Volgograd State University. University Education], 2004, iss. 7, pp. 117-118. 
T.В. Юдина. Классическое университетское образование в Волгоградском регионе: становление и развитие

\section{Information About the Author}

Taisiya V. Yudina, Doctor of Sciences (History), Professor, Department of Russian and World History, Archaeology, Volgograd State University, Prosp. Universitetsky, 100, 400062 Volgograd, Russian Federation, taisia.yudina@volsu.ru, https://orcid.org/0000-0003-0526-6484

\section{Информация об авторе}

Таисия Васильевна Юдина, доктор исторических наук, профессор кафедры отечественной и всеобщей истории, археологии, Волгоградский государственный университет, просп. Университетский, 100, 400062 г. Волгоград, Российская Федерация, taisia.yudina@volsu.ru, https://orcid.org/0000-0003-0526-6484 